\title{
Editorial
}

\section{From the Serotonin Model of Suicide to a Mental Pain Model of Suicide}

\author{
Jose de Leon ${ }^{a, c}$, d Enrique Baca-García ${ }^{b, e-i} \quad$ Hilario Blasco-Fontecilla ${ }^{\text {i-k }}$ \\ ${ }^{a}$ Mental Health Research Center, Eastern State Hospital, Lexington, Ky., and b Department of Psychiatry, New York \\ State Psychiatric Institute and Columbia University, New York, N.Y., USA; ${ }^{C}$ Psychiatry and Neurosciences Research \\ Group (CTS-549), Institute of Neurosciences, University of Granada, Granada, ${ }^{\mathrm{d} B i o m e d i c a l ~ R e s e a r c h ~ C e n t r e ~ i n ~}$ \\ Mental Health Net (CIBERSAM), Santiago Apóstol Hospital, University of the Basque Country, Vitoria-Gasteiz,

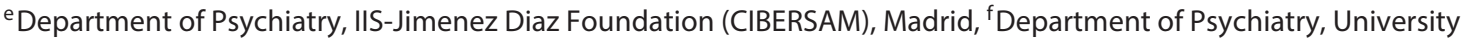 \\ Hospital Infanta Elena, Valdemoro, 9 Department of Psychiatry, University Hospital Rey Juan Carlos, Mostoles, and \\ hDepartment of Psychiatry, General Hospital of Villalba, 'ंAutonoma University, ${ }^{j}$ Department of Psychiatry, Puerta de \\ Hierro University Hospital (IDIPHIM, CIBERSAM), and kConsulting Asistencial Sociosanitario (CAS), Madrid, Spain
}

This is the story of a journey in suicide research. After 20 years, it may be time to abandon [1] the initial hypothesis (serotonin) and propose a unifying hypothesis for an extremely complex human behavior called suicide behavior (SB). This unifying hypothesis (mental pain) is new in the authors' articles but has been described in the literature for more than 20 years $[2,3]$.

\section{A Story with a Wrong Beginning: The Serotonin Model of SB}

This story started in the 1990s when optimism about the future of the biological approach in psychiatry in the late 20th century was at its peak [4]. Clinical psychiatrists approached suicide fundamentally as a medical issue; a textbook stated that ' $95 \%$ of suicides had a diagnosable psychiatric disorder' [5]. Research psychiatrists approached it using the serotonin model of suicide [6] and the associated clinical model based on a small sample of patients with depression [7]. Contributions criticizing the serotonin model had to be published in nonmainstream journals $[8,9]$.

\section{KARGER 125}

(c) 2015 S. Karger AG, Base

$0033-3190 / 15 / 0846-0323 \$ 39.50 / 0$

E-Mail karger@karger.com

www.karger.com/pps
After the first article on suicide attempts [10], the first author, influenced by the prevailing environment, advised his young mentee (the second author) that he needed to focus on biological factors, such as hormones and genes in the context of the serotonin model of SB, and on suicide attempters, who were much easier to study in a clinical setting than suicide completers.

\section{A Crucial Turning Point}

Instead of describing how we published many articles after progressively recruiting larger clinical samples of suicide attempters, we want to emphasize a very unsuccessful article which, after repeated attempts, was finally published in a journal not listed in PubMed [11].

To understand this article, some basic statistical concepts are needed. All psychiatrists know that, to publish a study, you need to obtain a 'statistically significant' value with a $\mathrm{p}<0.05$. Most psychiatrists do not know that this is an arbitrary convention established by statisticians long ago, and that other statistical concepts are more important in scientific research. The 'effect size' [12] is much

Jose de Leon, MD

Mental Health Research Center, Eastern State Hospital

1350 Bull Lea Road

Lexington, KY 40511 (USA)

E-Mail jdeleon@uky.edu 
more important than significance for understanding the relevance of variables in clinical settings; it measures how 'large' or 'small' the effect of a studied variable is. Without detailing the statistical problems with odds ratios (ORs) [13], most statisticians would probably agree that in a case-control study with a dichotomous dependent variable (e.g. SB or no SB) the OR is the recommended statistical method for measuring the effect size. The OR calculates the effect size of the association of SB with an independent variable (e.g. female sex) in a univariate cross-tabulation analysis (the $\chi^{2}$ test provides the $\mathrm{p}$ value). Logistic regression can then be used to adjust the OR for the effects of other confounding variables, such as age.

To summarize, in many articles we used ORs to measure the effect sizes of variables in SB using case-control designs. The unsuccessful article [11] focused on the effects of life events and personality traits in a sample of $>500$ subjects ( $>200$ cases and $>300$ controls). The findings were not new; life events and personality traits had huge effects, with an OR $>10$ when comparing SB cases with controls. What was new, and probably annoyed the reviewers from mainstream psychiatric journals, was our acknowledgment that in prior articles on SB the effect of biological measures, such as hormones and genes, was associated with lower ORs, which merely ranged from 1-2, while psychosocial factors appear to have ORs $>10$ [11].

\section{The Third Man}

Anyone familiar with movies would guess that a third man could only mean trouble. When the third author arrived to help the second author, the third man decided to pursue analysis to verify and clarify how life events and personality traits contribute to SB [14]. Then he proposed that, rather than biological or genetic variables, life stressors may be the best way to identify psychiatric patients at risk of suicide [15].

\section{Starting to Ask Painful Questions: What Is SB?}

A sophisticated reader may ask us to define SB. As a matter of fact, to get our articles published in scientific journals, we used a standard definition of suicide attempts [16]. Regarding SB, any clinician would probably agree that there are three major levels of SB: suicidal ideation, suicide attempt, and completed suicide [16].

Before moving on to the research problems of these three levels of SB, two painful acknowledgments need to be made. Our suicide research has been completed in Western countries, so our experience may have little relevance for SB in non-Western countries. Like others, when reviewing worldwide data [17], we found that completed suicide in developing or non-Western countries may be a different phenomenon because there 'socioeconomic and cultural factors appear to play a major contributing role in suicide' [17]. To be precise, our experience may apply only to Western countries in contemporary times; socioeconomic and cultural factors probably were more important in Western countries during the 19th century, as the French sociologist Durkheim [18] postulated [19].

The second acknowledgement is that any comments on the relationships between the frequencies of suicidal ideation, suicide attempts, and completed suicide are limited because there is no systematic research in Western countries using the same population to study frequencies of suicidal ideation, attempts, and completed suicide. Rates need to be estimated by forming a complex puzzle of multiple studies from multiple countries with multiple designs to try to provide a coherent understanding of SBs in Western countries [20].

The prevalence of suicidal ideation in Western countries ranges from 2 to $14 \%$ [21] but, as most of the people who report suicidal ideation do not attempt suicide [22], suicidal ideation must be essentially a different phenomenon from suicide attempts. Adding a 'wish to die' may increase the specificity of suicidal ideation [23]. Suicide attempts in Western countries are a reasonably good research target compared to completed suicide since attempters: (1) have a sufficient frequency (i.e. around $1-2 \%$ of the population [21] vs. an annual incidence of completed suicide measured per 10,000 individuals with values around 1 per 1,000 [24]) and (2) can be studied in hospitals versus using mortality samples. Thus, we, like most suicide researchers, study suicide attempters and try to extrapolate from them to suicide completers. However, from the statistical point of view, two major problems may exist when using this research strategy. They can be explained using two overlapping concepts: (1) suicide completers may be outliers within the group of suicide attempters, and (2) suicide attempters and completers may be different populations with relatively little overlap.

The concept of outliers is a complex statistical concept not easy to define [25] and refers to 'extreme' subjects not well represented by typical statistical measures such as the mean (a measure of central indexes); the outliers are the subjects in the 'tail areas' of the distribution [25]. Outliers are a major problem for approaches derived from evi- 
dence-based medicine (EBM); EBM resolves the problem by ignoring the outliers and focusing on the mean [26]. Heterogeneity, another possibly important issue in SB, is also a problem in EBM approaches [26-28].

A major statistical problem is created by assuming that the annual incidence of completed suicide in Western countries is approximately $0.02 \%$ [20] (or 20 per 100,000/ year) and that the prevalence of people reporting prior suicide attempts in cross-sectional surveys is approximately $2 \%$ [20]. The number of suicide completers is approximately 100 times lower than the number of attempters. This cannot be easily explained as a difference in prevalence (cross-section) versus incidence (annual rate). Completed suicide attempters are rare (probably outliers) within the attempter group. As a matter of fact, a metaanalysis estimated a $1 \%$ annual incidence of completed suicide after nonfatal self-harm acts, but this concept may be wider than suicide attempters and this estimation is limited by the study limitations [29].

There are few studies comparing attempters and completers within the same population, but the limited data available suggest that they may not even be the same population, since suicide attempts are mainly a psychiatric phenomenon. Attempters are patients frequently seen by psychiatrists, while the majority of completers are not seen by psychiatrists, although in approximately three fourths of the cases they may have been seen by primary care physicians [20]. As far as the authors can tell, attempters and completers are probably different but partly overlapping populations with some factors unique to completers [20, 30, 31]. A major methodological problem is that there are repeaters among suicide attempters. Some of them appear to be particularly prone to repetition $[32,33]$ and, therefore, can be 'counted' several times in studies of suicide attempters. Obviously, there are no repeaters among completers. Now it is time to explore the limits of the scientific approach in psychiatry [34].

\section{Even More Painful Questions: The Problems of Scientific Methodology in Psychiatry}

The previous section proposes that suicidal ideation, suicide attempts, and completed suicide may not be continuous phenomena and that those populations studied when researching ideation, attempts, or completed suicide may be different with some, but limited, overlap. These three levels may not operate like a continuous descent downhill but rather may function like three discontinuous steps. Particularly problematic from the statisti-

Suicide: From Serotonin to Mental Pain cal point of view is the hypothesis that most people with ideation do not attempt suicide; attempters, therefore, are 'outliers' within the group of people with suicidal ideation. This means that typical statistical designs/tests applied to people with suicidal ideation will not represent the attempters very well. Moreover, it would be catastrophic for the authors' research, which applied typical statistical designs/tests used with suicide attempters, if the attempters did not represent the completers very well. In summary, what we conceptually call SB appears to be made up of heterogeneous groups of phenomena.

Psychiatry deals with hybrid objects [35]. Jaspers [36], 100 years ago, described psychiatry as a hybrid science since he proposed that psychiatrists must combine the methods of the natural sciences which 'explain' phenomena and the methods of the social sciences which help us to 'understand' phenomena [36,37]. The concept of Pridmore et al. [38] of operationalized predicaments of suicide appears to be an initial reasonable approach combining causes (explanations) of and reasons (understanding) for suicidal acts. Psychological and social sciences may be very important in the study of suicidal ideation, which should be fundamentally understood rather than explained by biological 'causes'. We found that psychosocial variables, such as life stressors interacting with personality traits (different stressors may have different meanings for different individuals), may be very important in studying suicide attempters $[14,15]$. Biological variables may have little relevance as causes for suicide attempters. We think, but have no definitive data from the literature, that in Western countries biological variables such as genes may be much more important in completed suicide. When compared with attempters, suicide completers should probably include an overrepresentation of patients with bipolar disorder or severe cases of depression, which are probably intensely influenced by biological brain changes that may contribute to completed suicide.

In our studies two factors appear and reappear: completed/attempted suicide in the family and the use of alcohol during the attempt [39]. Due to the relatively low frequency $(\leq 10 \%)$ of familial suicide [39], our sample size was too small to explore two possible hypotheses (familial suicide is explained by shared genes or understood as a learned behavior). Similarly, we do not know if potential attempters use alcohol to disinhibit themselves and therefore attempt suicide or are people with no prior thought of suicide until they are intoxicated by alcohol. Our limited data [40] suggest that the latter is true; alcohol use may be more prominent in impulsive attempts with a low lethality. 
If suicidal ideation, suicide attempts, and completed suicide are not continuous linear phenomena but are influenced at different levels by the relative weight of psychosocial versus biological predictors, it may make little sense to search for biomarkers of SB in general [41]. More thoughtful approaches to developing biomarkers are needed in psychiatry [42].

\section{Human Bias and the Problem of Suicide Autopsies in Studying Completed Suicide}

The previous section posited that biological variables may have something more to offer in explaining completed suicide, but it acknowledged the limited available proof. Another reasonable hypothesis is that completed suicide in Western countries is largely a heterogeneous phenomenon. Menninger [43] insisted on the individuality of each suicide. In some patients it may be a planned decision in the absence of an obvious mental illness but while facing life challenges. In others it may be driven by abnormal biological changes in the brain, such as in cases of bipolar depression or severe major depression.

Establishing the relative importance of psychosocial versus biological factors is not easy because completed suicides are studied in detail via psychological autopsies [44-46], a retrospective assessment that can easily be biased by researcher or family member beliefs. Psychological autopsy studies frequently provide data on agreement among the study researchers [43] but do not comment on researcher or family biases. It is natural to think that groups of researchers who believe that completed suicide is mainly driven by a biological illness would easily agree among themselves that most of their psychological autopsy cases are explained by some biological illness [46]. Because a psychological autopsy is a medical procedure, researchers who are prone to being biased in favor of psychosocial explanations for completed suicide are likely to be underrepresented in psychological autopsies.

\section{Mental Pain as a Unifying Hypothesis for SB}

Twenty years ago, instead of encouraging the second author to study the serotonin hypothesis [6], the first author should have encouraged him to read the classic article on mental pain by Shneidman [2] entitled 'Suicide as Psychache'. The concept of mental pain goes back to Freud [47], and unbearable pain is central to the concepts of Shneidman [2] and Orbach et al. [3] and the escape theory of Baumeister [48]. Later, attempts [3, 49-54] were made to define the concept of mental pain more specifically than Shneidman [2] had. Scales of mental pain have been developed [55-56] including the Psychache Scale [57], the Mental Pain Questionnaire [58], and the Psychological Pain Assessment Scale [59]. As a matter of fact, there is a large body of literature that provides empirical evidence for the relationship between mental/psychological pain and suicide [2, 3, 49-54].

The authors currently believe that mental pain is what unifies all SBs, and they have started to use measures reflecting mental pain which suggest that $>90 \%$ of their patients with a suicide attempt report it [33].

Mental pain may be much more frequent in suicide attempts than the impulsive-aggressive behaviors associated with the serotonin model. If the hypothesis that suicidal ideation and probably many suicide attempts are better understood as mental pain than explained by biological causes, it is reasonable that these SBs would not be associated with any specific location in the brain or be conceptually amenable to brain imaging studies, since they may be secondary to other mental symptoms [37, 60]. Mental pain, on the other hand, may use the same brain mechanisms as other types of pain [61-63].

\section{ORs and Population-Attributable Risk}

In case-control studies, ORs can measure the effect size of associations at the level of the individual, but not at the level of the population. Let us assume that the death of a spouse is associated with an OR of 10.0 in a case-control study of suicide attempts. This effect would be small if only $5 \%$ of attempters had the death of a spouse as a stressor, but it would be much larger if $50 \%$ of the attempters presented this stressor. The population-attributable risk (PAR) [64], as opposed to ORs, measures the effect size at the level of the population. Imagine that you could totally eliminate the exposure to a factor associated with suicide; the PAR would describe how much suicide decreases in that population [64]. PAR, rather than OR, is the concept that makes sense whether you want to defend or argue against the hypothesis that depression explains $80-90 \%$ of completed suicides [65]. Few studies [66] of suicide attempts have tried to estimate the PAR because it requires access to the population from which the samples come.

Contemporary Western literature is limited and cannot be used to definitively demonstrate that biological 
variables, or serious mental illnesses such as bipolar disorder and/or severe depression, may be relatively more essential to the mental pain leading to completed suicide than to the mental pain leading to attempted suicide. A recent comprehensive meta-analysis [67] of suicide in bipolar disorder, when focused on completed suicide, provided an OR of 2.9 for a first-degree family history of suicide, but only $14 \%$ (21/149) of the completed suicides had a familial suicide history, indicating a very low PAR for familial suicide as in our studies [39]. In a recent prospective study of suicide attempts in the US population, accumulation of psychopathology was the best predictor of suicide attempts [68]. Similarly, a comprehensive review [69] of mood disorders proposed that comorbidity contributes to suicide acts in mood disorders.

Li et al. [70] are very courageous and assumed that the EBM approach works well in the study of completed suicide worldwide and that completed suicide is not a heterogeneous phenomenon. They calculated relative risks (RRs; a concept parallel to ORs) and PARs using metaanalysis. The RR for any mental disorder was 7.5 (CI 6.29.0) for males and 11.7 (CI 9.7-14.1) for females, compared to RRs of 2.1 (CI 1.5-2.8) for males and 1.5 (1.21.9) for females in the lowest socioeconomic groups. As a lower socioeconomic level is much more frequent than mental illness, it is not surprising that their PARs were of a similar magnitude [70].

\section{Need for Suicide Studies Focusing on PAR Associated with Mental Pain}

The extensive literature $[2,3,49-54]$ on mental pain in suicide and our experience that $>90 \%$ of our patients with suicide attempts report mental pain [33] indicate that mental pain may be associated with a high PAR for attempted suicide, but that is less certain than the mental pain PAR for completed suicide. Review articles estimating PAR for mental pain in suicide attempts and completed suicide are needed. Assuming that mental pain may be present in the majority of suicide attempts and completed suicides, this may be what unifies all SBs. On the other hand, how mental pain can be explained or understood [36-38] probably varies across SB levels. In suicidal ideation, mental pain is probably mainly an expression of psychosocial issues and their meaning to that individual. In our case-control studies of suicide attempts, we found that small ORs (range 1-2) were associated with biological variables, while much larger ORs $(>10)$ were associated with life stressors and per-

Suicide: From Serotonin to Mental Pain sonality traits [11], and that life stressors may have varying abilities to cause mental pain based on individual personality traits [14].

\section{Conclusion}

Recently, Healy [71] questioned the value of the serotonin hypothesis in depression. After 20 years of their own data serving as disconfirmation, it is time for the authors to abandon the serotonin hypothesis of suicide and clearly state that, according to our current knowledge, biological variables appear to make relatively small contributions to explaining suicide attempts. Starting 20 years ago with a theory of mental pain [2] as the unifying concept of SB would have been wiser. We are not sure how biological factors or severe affective disorders are relevant in completed suicide, but it may be time to acknowledge that it is legitimate to question the assumption of psychiatric textbooks that $80-90 \%$ of completed suicides are explained by depression [65]. Psychological autopsies are complex [44-46], but a recent meta-analysis [72] indicated a relatively low prevalence of affective disorders, i.e. $33-51 \%$, around the world, with $34 \%$ in North America, where there were high prevalences of substancerelated disorders (i.e. 40\%) and personality disorders (i.e. $13 \%)$. If these figures are correct, it is hard to defend the concept that biological variables are important in US completed suicides when it is not even clear that substance-related disorders or personality disorders are disorders in the medical sense [73].

To change the course of research in the area of suicide after 20 years of mistakes, we propose that suicide researchers should read again and again physician thinkers such as Jaspers [36] and Feinstein [25, 27, 74-76]. Jaspers [36], many years after leaving psychiatry, insisted that psychiatrists 'must learn to think' [73]. Feinstein [25, 27, 75] designed 'clinimetrics' $[74,76]$ to deal with complex medical concepts, such as SB. Clinimetric concepts have been applied to psychiatry [76-81]. Feinstein [27] also insisted that EBM $[26,28]$ has difficulties in dealing with outliers and heterogeneity, but we believe that outliers and heterogeneity are extraordinarily important concepts when looking for ways to understand suicide attempts in Western countries. We have found that biological variables may have small effects in explaining suicide attempts. It is also time to consider that one must be open to the hypothesis that mental illness may not explain the majority of completed suicides in Western countries, as some nonmedical researchers propose [65]. 


\section{Acknowledgments}

The authors thank Lorraine Maw, MA, for editorial assistance. The authors are grateful to the editor and reviewers who helped us to improve our thinking, further review the literature, and hopefully write a better editorial.

\section{Disclosure Statements}

This article received no support from any funding agency, commercial business, or not-for-profit institution. In the last 3 years, Dr. Blasco-Fontecilla has received lecture fees from Eli Lilly, AB-Biotics, Janssen, and Shire. Drs. de Leon and Baca-García declare no commercial conflicts of interest during the last 3 years.

\section{References}

1 Popper K: Conjectures and Refutations. New York, Harper Torchbooks, 1963.

2 Shneidman ES: Suicide as psychache. J Nerv Ment Dis 1993;181:145-147.

3 Orbach I, Mikulincer M, Sirota P, GilboaSchechtman E: Mental pain: a multidimensional operationalization and definition. Suicide Life Threat Behav 2003;33:219-230.

4 Shorter E: A History of Psychiatry: From the Era of the Asylum to the Age of Prozac. New York, Wiley, 1997.

5 McHugh P, Slavney PR: The Perspectives of Psychiatry, ed 2. Baltimore, Johns Hopkins University Press, 1998.

6 Mann JJ: The neurobiology of suicide. Nat Med 1998;4:25-30.

7 Mann JJ, Waternaux C, Haas GL, Malone KM: Toward a clinical model of suicidal behavior in psychiatric patients. Am J Psychiatry 1999;156:181-189.

8 Müller-Oerlinghausen B, Roggenbach J: Concretism in biological suicide research - are we eating the menu instead of the meal? Some thoughts on present research strategies. Pharmacopsychiatry 2002;35:44-49.

9 Roggenbach J, Müller-Oerlinghausen B, Franke L: Suicidality, impulsivity and aggression - is there a link to 5HIAA concentration in the cerebrospinal fluid? Psychiatry Res 2002;113:193-206.

-10 Baca-García E, Sánchez-González A, González Diaz-Corralero P, González García I, de Leon J: Menstrual cycle and profiles of suicidal behaviour. Acta Psychiatr Scand 1998; 97:32-35.

11 Baca-García E, Parra CP, Perez-Rodriguez MM, Diaz-Sastre C, Torres R, Saiz-Ruiz J, de Leon J: Psychosocial stressor may be strongly associated with suicide attempts. Stress Health 2007;23:191-198.

12 Kraemer HC, Kupfer DJ: Size of treatment effects and their importance to clinical research and practice. Biol Psychiatry 2006;59:990996.

13 Newcombe RG: A deficiency of the odds ratio as a measure of effect size. Stat Med 2006;25: 4235-4240.

14 Blasco-Fontecilla H, Baca-García E, Duberstein P, Perez-Rodriguez MM, Dervic K, SaizRuiz J, Courtet P, de Leon J, Oquendo MA: An exploratory study of the relationship between diverse life events and specific personality disorders in a sample of suicide attempters. J Pers Disord 2010;24:773-784.
5 Blasco-Fontecilla H, Delgado-Gomez D, Legido-Gil T, de Leon J, Perez-Rodriguez MM, Baca-García E: Can the Holmes-Rahe Social Readjustment Rating Scale (SRRS) be used as a suicide risk scale? An exploratory study. Arch Suicide Res 2012;16:13-28.

16 O'Carroll PW, Berman AL, Maris RW, Moscicki EK, Tanney BL, Silverman M: Beyond the Tower of Babel: a nomenclature for suicidology. Suicide Life Threat Behav 1996; 26:227-235.

-17 Blasco-Fontecilla H, Perez-Rodriguez MM, Garcia-Nieto R, Fernandez-Navarro P, Galfalvy $\mathrm{H}$, de Leon J, Baca-García E: Worldwide impact of economic cycles on suicide trends over 3 decades: differences according to level of development - a mixed effect model study. BMJ Open 2012;2:e00785.

18 Durkheim E: Suicide. New York, Free Press, 1897.

19 Berrios GE, Mohanna M: Durkheim and French psychiatric views on suicide during the 19th century: a conceptual history. Br J Psychiatry 1990;156:1-9.

20 Artieda-Urrutia P, Parra Uribe I, GarciaPares G, Palao D, de Leon J, Blasco-Fontecilla $\mathrm{H}$ : Management of suicidal behaviour: is the world upside down? Aust NZ J Psychiatry 2014;48:399-401.

-21 ten Have M, de Graaf R, van Dorsselaer S, Verdurmen J, van 't Land H, Vollebergh W, Beekman A: Incidence and course of suicidal ideation and suicide attempts in the general population. Can J Psychiatry 2009;54:824-833.

22 Klonsky ED, May AM: Differentiating suicide attempters from suicide ideators: a critical frontier for suicidology research. Suicide Life Threat Behav 2014;44:1-5.

23 Baca-García E, Perez-Rodriguez MM, Oquendo MA, Keyes KM, Hasin DS, Grant BF, Blanco C: Estimating risk for suicide attempt: are we asking the right questions? Passive suicidal ideation as a marker for suicidal behavior. J Affect Disord 2011;134:327-332.

24 Centers for Disease Control and Prevention: Regional variations in suicide rates - United States, 1990-1994. MMWR Morb Mortal Wkly Rep 1997;46:789-793.

25 Feinstein A: Multivariable Analysis: An Introduction. New Haven, Yale University Press, 1996.

26 de Leon J: Evidence-based medicine versus personalized medicine: are they enemies? J Clin Psychopharmacol 2012;32:153-164.
27 Feinstein AR, Horwitz RI: Problems in the 'evidence' of 'evidence-based medicine'. Am J Med 1997;103:529-535.

28 Fava GA, Guidi J, Rafanelli C, Sonino N: The clinical inadequacy of evidence-based medicine and the need for a conceptual framework based on clinical judgment. Psychother Psychosom 2015;84:1-3.

29 Owens D, Horrocks J, House A: Fatal and non-fatal repetition of self-harm: systematic review. Br J Psychiatry 2002;181:193-199.

30 Giner L, Blasco-Fontecilla H, Mercedes Perez-Rodriguez M, Garcia-Nieto R, Giner J, Guija JA, Rico A, Barrero E, Luna MA, de Leon J, Oquendo MA, Baca-García E: Personality disorders and health problems distinguish suicide attempters from completers in a direct comparison. J Affect Disord 2013;151: 474-483.

-31 DeJong TM, Overholser JC, Stockmeier CA: Apples to oranges? A direct comparison between suicide attempters and suicide completers. J Affect Disord 2010;124:90-97.

- 32 Blasco-Fontecilla H, Artieda-Urrutia P, Berenguer-Elias N, Garcia-Vega JM, Fernandez-Rodriguez M, Rodriguez-Lomas C, Gonzalez-Villalobos I, Iruela-Cuadrado L, de Leon J: Are major repeater patients addicted to suicidal behavior? Adicciones 2014;26: 321-333.

33 Blasco-Fontecilla H, Baca-García E, Courtet P, García Nieto R, de Leon J: Horror vacui: emptiness might distinguish between major suicide repeaters and nonmajor suicide repeaters: a pilot study. Psychother Psychosom 2015;84:117-119.

34 de Leon J: Is psychiatry scientific? A letter to a 21 st century psychiatry resident. Psychiatry Investig 2013;10:205-217.

35 Berríos GE: Psychiatry and its objects. Rev Psiquiatr Salud Ment 2011;4:179-182.

36 Jaspers K: General Psychopathology (translated from the German ed 7 by Hoenig J and Hamilton MH). Manchester, Manchester University Press, 1963.

37 de Leon J: One hundred years of limited impact of Jaspers's General Psychiatry in the US psychiatry. J Nerv Ment Dis 2014;202:79-87.

38 Pridmore S, Kuipers P, Zainab AM, Restifo S, Lee A, Appleton J: A pilot investigation of the Operationalized Predicaments of Suicide (OPS) framework. Malays J Med Sci 2012;19: $50-56$. 
-39 Baca-García E, Perez-Rodriguez MM, SaizGonzalez D, Basurte-Villamor I, Saiz-Ruiz J, Leiva-Murillo JM, de Prado-Cumplido M, Santiago-Mozos R, Artés-Rodríguez A, de Leon J: Variables associated with familial suicide attempts in a sample of suicide attempters. Prog Neuropsychopharmacol Biol Psychiatry 2007;31:1312-1316.

-40 Baca-García E, Diaz-Sastre C, Basurte E, Prieto R, Ceverino A, Saiz-Ruiz J, de Leon J: A prospective study of the paradoxical relationship between impulsivity and lethality of suicide attempts. J Clin Psychiatry 2001;62:560564.

41 Le-Niculescu H, Levey DF, Ayalew M, Palmer L, Gavrin LM, Jain N, Winiger E, Bhosrekar S, Shankar G, Radel M, Bellanger E, Duckworth H, Olesek K, Vergo J, Schweitzer R, Yard M, Ballew A, Shekhar A, Sandusky GE, Schork NJ, Kurian SM, Salomon DR, Niculescu AB 3rd: Discovery and validation of blood biomarkers for suicidality. Mol Psychiatry 2013;18:1249-1264.

-42 Fava GA, Guidi J, Grandi S, Hasler G: The missing link between clinical states and biomarkers in mental disorders. Psychother Psychosom 2014;83:136-141.

43 Menninger K: Man Against Himself. San Diego, Harcourt Brace Jovanavich, 1956.

44 Pouliot L, De Leo D: Critical issues in psychological autopsy studies. Suicide Life Threat Behav 2006;36:491-510.

-45 Sher L: Psychological autopsy studies: past, present, and future. Aust NZ J Psychiatry 2013;47:884.

46 Pridmore S: Medicalisation of suicide. Malays J Med Sci. 2011;18:78-83.

-47 Fleming M: On mental pain: from Freud to Bion. Int Forum Psychoanal 2008;17:27-36.

48 Baumeister RF: Suicide as escape from self. Psychol Rev 1990;97:90-113.

49 Tossani E: The concept of mental pain. Psychother Psychosom 2013;82:67-73.

-50 Olié E, Guillaume S, Jaussent I, Courtet P, Jollant F: Higher psychological pain during a major depressive episode may be a factor of vulnerability to suicidal ideation and act. J Affect Disord 2010;120:226-230.

51 Meerwijk EL, Weiss SJ: Toward a unifying definition of psychological pain. J Loss Trauma 2011;16:402-412.

52 Orbach I: Mental pain and suicide. Isr J Psychiatry Relat Sci 2003;40:191-201.

53 Meerwijk EL, Weiss SJ: Toward a unifying definition: response to 'the concept of mental pain'. Psychother Psychosom 2014;83:62-63.
Tossani E: Definition versus measurement of mental pain: a reply to Meerwijk and Weiss. Psychother Psychosom 2014;83:64.

55 Li H, Xie W, Luo X, Fu R, Shi C, Ying X, Wang N, Yin Q, Wang X: Clarifying the role of psychological pain in the risks of suicidal ideation and suicidal acts among patients with major depressive episodes. Suicide Life Threat Behav 2014;44:78-88.

56 Mee S, Bunney BG, Reist C, Potkin SG, Bunney WE: Psychological pain: a review of evidence. J Psychiatr Res 2006;40:680-690.

57 Holden RR, Mehta K, Cunningham EJ, McLeod LD: Development and preliminary validation of a scale of psychache. Can J Behav Sci 2001;33:224-232.

58 Orbach I, Mikulincer M, Sirota P, GilboaSchechtman E: Mental pain: a multidimensional operationalization and definition. Suicide Life Threat Behav 2003;33:219-230.

59 Mee S, Bunney BG, Bunney WE, Hetrick W, Potkin SG, Reist C: Assessment of psychological pain in major depressive episodes. J Psychiatr Res 2011;45:1504-1510.

60 Berrios GE, Markova IS: Symptoms - historical perspective and effect on diagnosis; in Blumenfield M, Strain JJ (ed): Psychosomatic Medicine. Philadelphia, Lippincott Williams \& Wilkins, 2006, pp 27-38.

61 Ducasse D, Courtet P, Olié E: Physical and social pains in borderline disorder and neuroanatomical correlates: a systematic review. Curr Psychiatry Rep 2014;16:443.

62 Meerwijk EL, Ford JM, Weiss SJ: Brain regions associated with psychological pain: implications for a neural network and its relationship to physical pain. Brain Imaging Behav 2013;7:1-14.

63 Wager TD, Atlas LY, Lindquist MA, Roy M, Woo C-W, Kross E: An fMRI-based neurologic signature of physical pain. N Engl J Med 2013;368:1388-1397.

64 Gefeller O: The concept of attributable risk in epidemiology: yesterday, today and tomorrow. Stat Methods Med Res 2001;10:157-158.

65 Shahtahmasebi S: Examining the claim that $80-90 \%$ of suicide cases had depression. Front Public Health 2013;6;1:62.

66 Baca-García E, Diaz-Sastre C, Ceverino A, Saiz-Ruiz J, Diaz FJ, de Leon J: Association between the menses and suicide attempts: a replication study. Psychosom Med 2003;65: 237-244.
67 Schaffer A, Isometsä ET, Tondo L, H Moreno D, Turecki G, Reis C, Cassidy F, Sinyor M, Azorin JM, Kessing LV, Ha K, Goldstein T, Weizman A, Beautrais A, Chou YH, Diazgranados N, Levitt AJ, Zarate CA Jr, Rihmer Z, Yatham LN: International Society for Bipolar Disorders Task Force on Suicide: meta-analyses and meta-regression of correlates of suicide attempts and suicide deaths in bipolar disorder. Bipolar Disord 2015;17:1-16.

68 Hoertel N, Franco S, Wall MM, Oquendo MA, Kerridge BT, Limosin F, Blanco C: Mental disorders and risk of suicide attempt: a national prospective study. Mol Psychiatry 2015;20:718-726.

69 Isometsä E: Suicidal behaviour in mood disorders - who, when, and why? Can J Psychiatry 2014;59:120-130.

70 Li Z, Page A, Martin G, Taylor R: Attributable risk of psychiatric and socio-economic factors for suicide from individual-level, populationbased studies: a systematic review. Soc Sci Med 2011;72:608-616.

71 Healy D: Serotonin and depression. BMJ 2015;350:h1771.

72 Arsenault-Lapierre G, Kim C, Turecki G: Psychiatric diagnoses in 3,275 suicides: a metaanalysis. BMC Psychiatry 2004;4:37.

73 de Leon J: Is psychiatry only neurology? Or only abnormal psychology? Déjà vu after 100 years. Acta Neuropsychiatr 2015;27:69-81.

74 Feinstein AR: Clinimetrics. New Haven, Yale University Press, 1987.

-75 Knottnerus JA, Tugwell P: After ARF. J Clin Epidemiol 2002;55:1159-1160.

76 Fava GA, Belaise C: A discussion on the role of clinimetrics and the misleading effects of psychometric theory. J Clin Epidemiol 2005; 58:753-756.

77 Fava GA, Tomba E, Sonino N: Clinimetrics: the science of clinical measurements. Int J Clin Pract 2012;66:11-15.

78 Tomba E, Offidani E: A clinimetric evaluation of allostatic overload in the general population. Psychother Psychosom 2012;81:378379.

79 Fava GA, Rafanelli C, Tomba E: The clinical process in psychiatry: a clinimetric approach. J Clin Psychiatry 2012;73:177-184.

80 Fava GA, Guidi J, Semprini F, Tomba E, Sonino $\mathrm{N}$ : Clinical assessment of allostatic load and clinimetric criteria. Psychother Psychosom 2010;79:280-284.

-81 Tomba E, Bech P: Clinimetrics and clinical psychometrics: macro- and micro-analysis. Psychother Psychosom 2012;81:333-343. 